\title{
Erratum to: Biomarkers for hepatocellular carcinoma
}

\author{
Goshi Shiota $・$ Norimasa Miura
}

Published online: 26 May 2012

(c) Springer 2012

\section{Erratum to: Clin J Gastroenterol \\ DOI 10.1007/s12328-012-0301-x}

In the above-cited article, in Table 1 the source of the table was omitted in the title. The title of the table should be shown as follows:

Table 1 Sensitivity/specificity of biomarkers for HCC (reproduced from [67], with permission).

The online version of the original article can be found under doi:10.1007/s12328-012-0301-x.

G. Shiota $(\bowtie)$

Division of Molecular and Genetic Medicine,

Department of Genetic Medicine and Regenerative Therapeutics,

Graduate School of Medicine, Tottori University,

Yonago 683-8503, Japan

e-mail: gshiota@med.tottori-u.ac.jp

N. Miura

Division of Pharmacotherapeutics,

Department of Pathophysiological and Therapeutic Science,

Faculty of Medicine, Tottori University,

Yonago 683-8503, Japan 